\title{
COMPRESSIVE PROPERTIES OF GEOPOLYMER MATRIX COMPOSITES
}

\author{
Robin Hron ${ }^{1, a}$, František Martaus ${ }^{1}$ and Martin Kadlec ${ }^{1}$ \\ ${ }^{1}$ VZLU - Czech Aerospace Research Centre, Czech Republic
}

\begin{abstract}
Polymer based resin is presently the most used resin for preparing of composites constructions, because of its undisputable benefits; however, there are some limits. The aircraft industry has especially strict requirements for fire, smoke and toxicity (FST) properties which are limited when using organic polymers. Conventional polymer resins resist to temperatures usually up to $120^{\circ} \mathrm{C}$ and then they lose stiffness and strength. However, geopolymer matrix is a new type of resin with high potential for cost-efficient applications dealing with temperatures up to $1200^{\circ} \mathrm{C}$.

This paper presents compressive properties of a new geopolymer resin and a fibre reinforced composite with the geopolymer matrix (geocomposite). The effect of a harsh environment exposition on the strength was also evaluated, specifically the impact of the exposure in hot-wet and salt mist conditions. Samples were tested in accordance with ASTM D695 in case of pure resin and in accordance with ASTM D6641 in case of the geocomposite. All tests were performed at room temperature and additionally, pure geopolymer resin was tested at $400{ }^{\circ} \mathrm{C}$. The high temperature caused $35 \%$ decrease of the compressive strength in comparison with the room temperature. Geopolymers behaves like a ceramic and have some unique properties such as high thermal stability, non-flammability and do not generate toxic smoke and fumes.
\end{abstract}

\section{Introduction}

At present, there is an increasing need for materials eliminating fatal results of fire in case of aircraft accident [1]. Currently used organic matrix composites formally meet requirements such as FAR 25, appendix F; nevertheless, in the event of real fire they quickly deteriorate at temperatures above $300{ }^{\circ} \mathrm{C}$ emitting toxic fumes and gases. True non-flammability of present-day composites is limited to minutes [2]. The material, known as geopolymer (first geopolymer resin was described in France by J. Davidovits in 1979 [3]) withstands temperatures of over $1000^{\circ} \mathrm{C}$ and can be utilized as matrix in fibre reinforced composites. The use of geopolymer materials looks like a good choice for constructions with increased requirements on fire, smoke and toxicity (FST) properties. The main advantages of geopolymers are the excellent temperature stability; fire resistance with no generation of toxic fumes and smokes, low thermal conductivity and good specific strength [4-7]. The material behaves like a ceramic, but does not require high processing temperatures or pressures, so it can be worked up like common organic resins [8]. On the other hand, the geopolymer materials have also disadvantages

\footnotetext{
${ }^{\text {a } C o r r e s p o n d i n g ~ a u t h o r ~: ~ h r o n @ v z l u . c z ~}$
} 
when compared with commonly used polymer resins. The most significant are lower mechanical properties.

\section{Experiment}

Compressive properties of a new geopolymer resin and carbon fibre reinforced geopolymer composite (geocomposite) were examined. The influence of the temperature and environment (hot-wet and salt mist conditions) on these properties was also investigated in the experiment.

Samples were tested in accordance with the ASTM D695 - Standard Test Method for Compressive Properties of Rigid Plastics [9], in case of pure resin and in accordance with ASTM D6641 - Standard Test Method for Compressive Properties of Polymer Matrix Composite Materials Using a Combined Loading Compression (CLC) Test Fixture [10], in case of geocomposite samples.

\subsection{Material}

Geopolymer resin was prepared by mixing of the components listed in Table 1. The table also shows the weight and weight ratio of the individual components. In the first step, pure geopolymer resin was prepared (by mixing components 1-5) and then short ceramic and carbon fibres were added.

Table 1. Geopolymer resin composition.

\begin{tabular}{|c|l|c|c|}
\hline & \multicolumn{1}{|c|}{ Component } & $\mathrm{m}(\mathrm{g})$ & wt. \% \\
\hline 1 & $\mathrm{SiO}_{2}($ Thermal silica) & 513.24 & 35.24 \\
\hline 2 & $\mathrm{Al}(\mathrm{OH})_{3}$ & 453.32 & 28.74 \\
\hline 3 & $\mathrm{H}_{2} \mathrm{O}$ & 158.48 & 10.05 \\
\hline 4 & $\mathrm{NaOH}$ & 111.16 & 7.05 \\
\hline 5 & $\mathrm{KOH}$ & 163.80 & 10.39 \\
\hline 6 & Ceramic fiber LYTX-311-L & 84 & 5.33 \\
\hline 7 & Carbon chopped fiber Tenax ${ }^{\circledR}-\mathrm{A}$ HT C124 3 mm & 93.24 & 5.91 \\
\hline$\Sigma$ & & 1577 & 100 \\
\hline
\end{tabular}

Unidirectional carbon fibre tape, type TCU175, 3K [11] was used for geocomposite samples.

\subsection{Test samples}

Resin samples were prepared by casting the geopolymer mixture into the form. The filling of the geopolymer resin into the forms was carried out on a vibration table. After casting, the test samples were cured at $80{ }^{\circ} \mathrm{C} / 20$ hour. The test samples were then extruded from the form and tempered at $80{ }^{\circ} \mathrm{C} / 9$ hours $+100{ }^{\circ} \mathrm{C} / 12$ hours at the chamber. Final tempering was done in a cascade mode from 105 to $170{ }^{\circ} \mathrm{C}$.

Carbon fibre-reinforced polymer (CFRP) samples were prepared by cutting of the test panel. Test panel were prepared by contact laminating (standardly $400 \mathrm{~g}$ of resin $/ \mathrm{m}^{2}$ of fabric). Parameters of the curing cycle were as follows: heat up rate $2-8{ }^{\circ} \mathrm{C} / \mathrm{min}$, cured temperature $85 \pm 3^{\circ} \mathrm{C}$, dwell time 18 hours, vacuum min. $-80 \mathrm{kPa}$, cooling rate max. $8{ }^{\circ} \mathrm{C} / \mathrm{min}$. Test samples were cut from the test panel by a diamond blade.

The surface protection of all test samples to improve the resistance to external influence (especially by water) was performed by immersing test samples into a mixture of ethyl silicates of polysilic acids, concurrently with Dynasylan Silbond 40 [12]. Test matrix is showed in Table 2. 
Table 2. Test matrix

\begin{tabular}{|c|c|c|c|c|}
\hline Sample type & Exposure & Test temperature & No. of samples & Test method \\
\hline \multirow{4}{*}{$\begin{array}{c}\text { Geopolymer } \\
\text { resin }\end{array}$} & - & $\mathrm{RT}$ & 5 & \multirow{2}{*}{ ASTM D695 } \\
\cline { 2 - 4 } & \multirow{2}{*}{ hot-wet } & $400^{\circ} \mathrm{C}$ & 5 & \multirow{2}{*}{} \\
\cline { 2 - 4 } & \multirow{2}{*}{ salt mist } & $\mathrm{RT}$ & 5 & \\
\cline { 2 - 4 } & & $400^{\circ} \mathrm{C}$ & 5 & \multirow{2}{*}{ ASTM D6641 } \\
\cline { 2 - 4 } $\begin{array}{c}\text { Geocomposite } \\
\text { samples }\end{array}$ & - & $\mathrm{RT}$ & 5 & \\
\cline { 2 - 4 } & hot-wet & $\mathrm{RT}$ & 5 & \\
\cline { 2 - 4 } & salt mist & $\mathrm{RT}$ & 5 & \\
\hline
\end{tabular}

\subsection{Exposure}

Exposure in salt mist (SM) was performed according to standard EN ISO 9227 with concentration of the $\mathrm{NaCl}$ solution $50 \mathrm{~g} / \mathrm{l}$, temperature $35{ }^{\circ} \mathrm{C}$ and relative humidity $100 \%$. Hot/Wet (HW) condition at $70{ }^{\circ} \mathrm{C}$ and $85 \%$ relative humidity until saturation per EN 60068-2-78, was applied.

\subsection{Tests}

All tests were performed in the testing laboratory of Strength of structure department of the Czech aerospace research centre according to valid standards on the mechanical loading machine Instron $55 \mathrm{R} 1185$.

\subsubsection{Pure resin compression test}

Test was performed according to ASTM D695. Specimen was placed between compressive plates parallel to the specimen surface (platen surfaces parallel was within $0.03 \mathrm{~mm}$ across the sample contact area), and compressed along its major axis at constant rate of displacement $(1.0 \mathrm{~mm} / \mathrm{min})$ until the specimen fracture occurred. The test assembly is shown in Figure 1a and Figure 1b for RT and elevated temperature, respectively.

\subsubsection{Coupon compression test}

Test was performed according to ASTM D6641. Specimen was fixed in the combined loading compression (CLC) test fixture so that the end of the specimen was in flush with the ends of the CLC test fixture. All screws on the CLC fixture were screwed to $2.5 \mathrm{Nm}$. The assembled fixture was placed between well-aligned, fixed flat platens (platen surfaces parallel was within $0.03 \mathrm{~mm}$ across the fixture base) and compressed along its longitudinal axis at constant rate of displacement $(1.3 \mathrm{~mm} / \mathrm{min})$ until the failure. To determine the compression modulus of the geopolymer, extensometer Instron 2620-601 with gauge length $12.5 \mathrm{~mm}$ was attached on the test sample. The test assembly is shown in Figure 1c. 


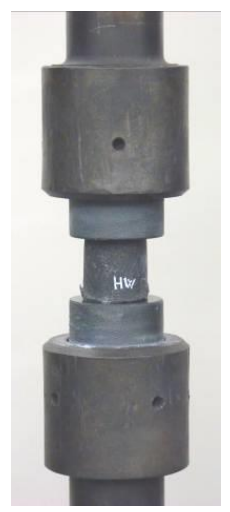

a)

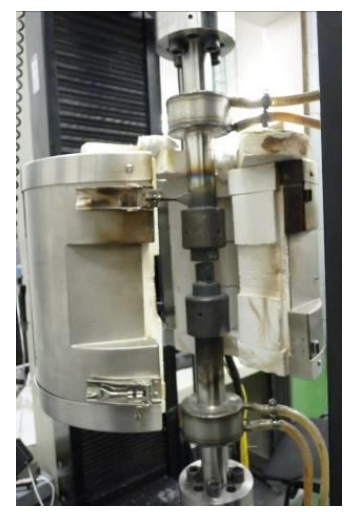

b)

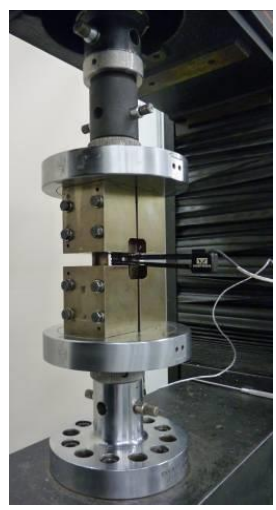

c)

Figure 1. Test assemblies: a) pure resin at RT, b) pure resin at temperature chamber, c) geocomposite sample in CLC test fixture

\section{Results}

All measured results were tested by Dixon's Q test on presence of outliers. Test was performed for significance level 0.05 and outlying values were not included into the test evaluation. A T-test was performed for determination whether the individual sets are significantly different from each other. Statistical significance 0.05 was chosen.

\subsection{Compressive strength of the pure resin.}

The highest average compressive strength of $43.6 \mathrm{MPa}$ was measured on samples tested at room temperature without previous exposition in the harsh environment. Mean values with standard deviations are shown in Figure 2. The measured data showed that the elevated temperature of $400{ }^{\circ} \mathrm{C}$ decreased in all cases the compressive strength compared to RT sets. The decrease was evaluated as statistically significant for all the sets. In the case samples measured at RT after the environmental exposition, the hot-wet condition had not statistically significant influence on compressive strength. However, the effect of salt mist was statistically significant. For the tests at $400{ }^{\circ} \mathrm{C}$, the influence of the environment was statistically insignificant. Typical failure modes of the geopolymer resin samples are showed in Figure $3 \mathrm{a}$.

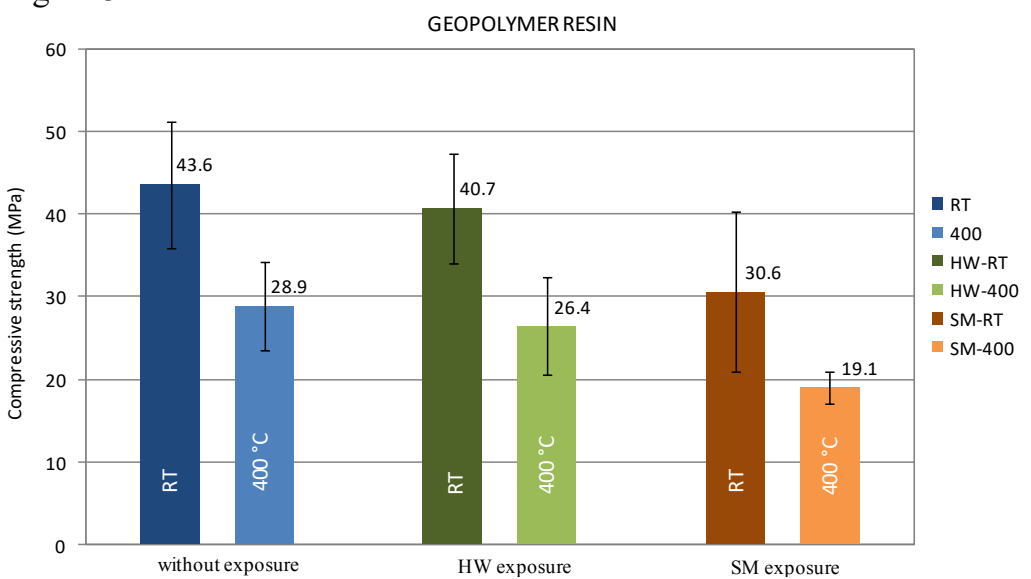

Figure 2. Compressive strength - mean values with sample standard deviation bars, geopolymer resin. 


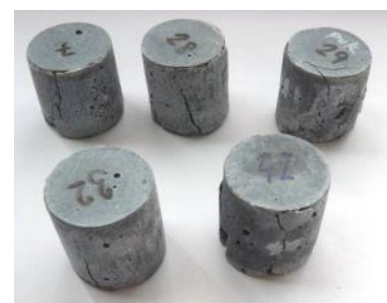

a)

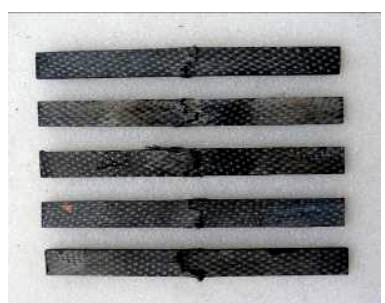

b)

Figure 3. Specimens after the test: a) pure geopolymer resin, b) geocomposite.

\subsection{Compressive strength and modulus of the geocomposite}

The highest average compressive strength of $225.5 \mathrm{MPa}$ was measured for set that was not exposed in the environment. Average compressive strength measured on the samples exposed at hot-wet conditions was approximately by $26 \%$ lower $(168.1 \mathrm{MPa})$ compared to the baseline and average strength of salt mist exposed sample was by $21 \%$ lower $(178.5 \mathrm{MPa})$ than for the not exposed set. Typical failure mode is shown in Figure $3 \mathrm{~b}$ and mean values with standard deviations are shown in Figure 4a.

Differences between the measured compressive modulus of elasticity were evaluated as statistically insignificant. The difference between the highest and lowest measured average compressive modulus of elasticity was less than $15 \%$ (96.8 GPa for not exposed set, 83.0 GPa for hot-wet set and 86.4 for salt mist set). Mean values of the compressive modulus with standard deviations are shown in Figure 4b.

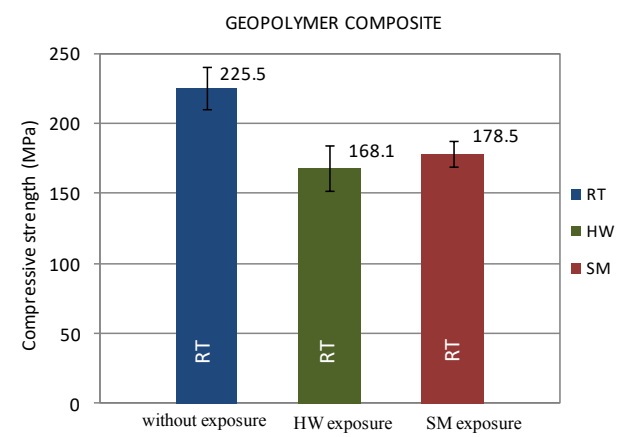

a)

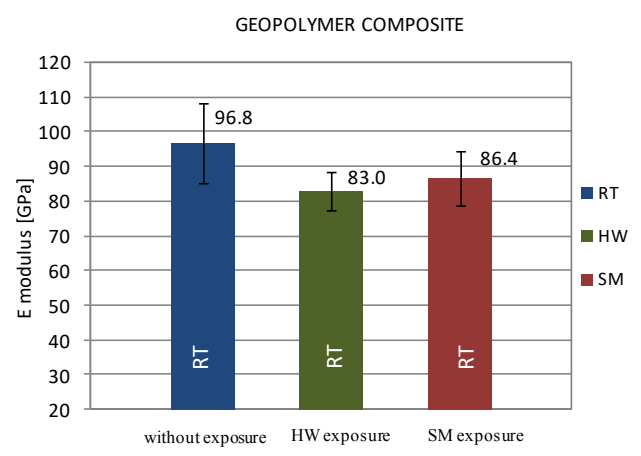

b)

Figure 4. Compressive strength and modulus - mean values with sample standard deviation bars, geocomposite.

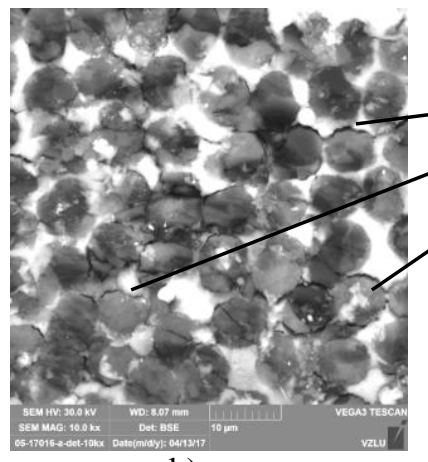

b)

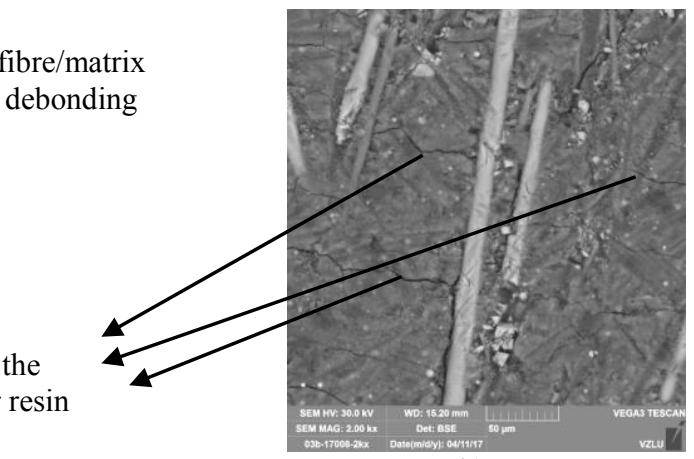

b)

Figure 5. Microscopy analysis before testing: a) matrix debonding from fibres, b) cracks in the resin. 


\subsection{Microstructure analysis}

Microstructure analysis using scanning electron microscopy was performed on selected specimens before the testing; see Figure 5. The analysis showed that in some places the resin is debonded from the carbon fibres. Cavities and cracks in the pure resin were observed. The origin of these defects was probably in the shrinkage of the geopolymer resin. These defects were probably the cause of a large scatter of the measured values.

\section{Conclusion}

The research of geopolymer based materials showed that compressive strength of pure geopolymer resin at $400{ }^{\circ} \mathrm{C}$ was decreased by approx. $35 \%$ in comparison with the room temperature values. Furthermore, the exposure of salt mist was significantly deteriorating on the strength of geopolymer resin for both test temperatures. On the other hand, the influence of the hot-wet environment had insignificant influence on measured compressive strength.

For geocomposite samples, the effect of the harsh environment on values of compressive strength was significant for both the cases reaching up to $25 \%$ decrease. However, the influence of the environment on compressive modulus of the geocomposite samples was statistically insignificant.

The measured values clearly demonstrated that the geopolymer based materials still retain approximately $65 \%$ of the strength at $400{ }^{\circ} \mathrm{C}$. Compared to that, conventional polymeric materials would be disintegrated at that temperature.

Geopolymeric materials can be recommended for the structures in airplanes interiors where strict requirements for fire, smoke and toxicity are defined according to FAR 25 regulations.

\section{Acknowledgement}

This research was funded by the European Union in the frame of "Future Sky Safety" project, the Joint Research Initiative Safety P7, project "Mitigate risk of fire, smoke and fumes".

\section{References}

1. R. E. Lyon, "Fire Safe Aircraft Cabin Materials," in Fire and Polymers, ACS Symposium Series Number 599, G.L. Nelson, ed., American Chemical Society, Washington, D.C., p. 618, 1995.

2. R. E. Lyon, Fire Response of Geopolymer Structural Composites, DOT/FAA/AR-TN95/22, 1996

3. J. Davidovits, J. L. Sawyer. Early high-strength mineral polymer, U. S. Patent 4,509,985, United States, 1985.

4. J. Davidovits, Geopolymer Chemistry \& Applications, Institute Géopolymèr, France, 2008.

5. R. E. Lyon, et. all. Fire resistant aluminosilicate composites. Fire and materials 21(2) pp. 67-73, 1997.

6. Duxson, P. et al. (2007). Geopolymer technology: the current state of the art. Journal of Materials Science 42(9): pp. 2917-2933.

7. T. D. Hung, et all. New Generation of Geopolymer Composite for Fire-Resistance, Advanced in Composite Materials - Analysis of natural and Man-Made Materials, InTech, 2011

8. J. Davidovits, 30 Years of Successes and Failures in Geopolymer Applications - Market trends and Potential breakthroughs. Geopolymer 2002 Conference, Melbourne, Australia, Geopolymer Institute, pp. 1-16, 2002.

9. ASTM D695-15 - Standard Test Method for Compressive Properties of Rigid Plastics.

10. ASTM D6641-16 - Standard Test Method for Compressive Properties of Polymer matrix Composite materials Using a Combined loading Compression (CLC) Test Fixture.

11. Fabrics for composites, Multiaxial knitted fabric MC-45C-0200, Product Data Sheet, 2014.

12. Evonik Industries AG, Dynasylan 40, Product Data Sheet, 2011. 